\title{
Mudanças institucionais nas políticas de direitos autorais na comunicação científica: discussão teórica e realidade brasileira
}

\author{
Larissa Melo Bezerra de Oliveira \\ Sely Maria de Souza Costa
}

Universidade de Brasília - UnB, Brasil

\section{REVIEW}

\begin{abstract}
Resumo
Objetivo. Apresenta revisão da literatura relevante a respeito dos tópicos comunicação científica, acesso aberto à literatura científica, papel das instituições no contexto de políticas públicas e o direito autoral no acesso aberto à literatura científica. Método. Trata-se de estudo analítico-descritivo que se baseou no uso do método de pesquisa bibliográfica em conjunto com análise documental, em uma abordagem qualitativa, visando a identificar questões relevantes à construção de referencial teórico sobre os temas estudados.

Resultados. Com base na literatura e em documentos legais, construiu-se referencial teórico para o estudo do direito autoral na comunicação científica, no contexto do acesso aberto, levando em conta a teoria da ACF, cujo enfoque principal é a formação de coalizões. Apresenta nova proposta de modelo do processo de comunicação científica, em que são incluídas etapas relacionadas com o direito autoral. Situa a discussão no contexto brasileiro e na importância das instituições nas políticas públicas.

Conclusões. A abordagem da ACF oferece um modelo para identificação de coalizões que realmente reflitam a Agenda de uma nação no contexto da comunicação científica e do movimento do acesso aberto.
\end{abstract}

Palavras-chave

Direito autoral ; Comunicação científica ; Acesso aberto ; Literatura científica ; Políticas públicas ; Instituições ; Brasil

Institutional changes in copyright policies for scientific communication: theoretical discussion and Brazilian context

\begin{abstract}
Objective. The study presents relevant items of a literature review on scholarly communication, open access to scientific literature, the role of the institutions in the context of public policies, as well as author rights and open access to scien tific literature.

Method. The work consists of an analytic-descriptive study based on a bibliographic search and a documental analysis, within a qualitative approach. It aimed to identify relevant issues to the construction of a theoretical framework on the themes studied.

Results. Based on the literature and legal document analysis, a theoretical framework has been built to the study of author rights in scholarly communication in the context of open access. It takes account of the ACF, which focuses on coalitions. A new model to the scholarly communication process is presented, including activities related to author rights. The study centers its focus on the Brazilian context and on the importance of institutions to public policies.

Conclusions. The ACF approach offers a model to the identification of coalitions that really reflects a nation Agenda in the context of scholarly communication and the open access.
\end{abstract}

\section{Keywords}

Copyright ; Scholarly communication ; Open access ; Scientific literature ; Public policies ; Institutions ; Brazil 


\section{Introdução}

Este artigo apresenta a discussão teórica de estudo de mestrado que propõe um modelo de política de direitos autorais para repositórios institucionais em universidades. Com base na análise de modelos identificados na literatura, o estudo objetiva identificar que modelo teórico de política é mais apropriado ao Movimento do Acesso Aberto. Adicionalmente, o estudo visa a avaliar como esse modelo reflete a realidade brasileira. Para isso são discutidas três questões principais. A primeira se relaciona com o processo de política pública. A segunda discute, dentro do contexto de políticas, os direitos autorais, desde aspectos históricos até mudanças introduzidas pelo uso de tecnologias da informação na comunicação científica. Finalmente, apresenta perspectivas atuais da comunicação científica no contexto do acesso aberto, visando à construção do referencial necessário ao acesso aberto no Brasil. É importante notar que as teorias discutidas no estudo buscam explicar os processos de políticas públicas por meio da análise do conteúdo da consulta pública que teve a finalidade de discutir o projeto de lei que se destina a revisão da Lei 9.610/98, atual lei de Direitos Autorais.

Nesse contexto, instituições políticas - diferentemente de instituições sociais ou econômicas - constituem "normas que governam o uso legítimo do poder" (BOBBIO, 1998, p. 47). De fato, é inegável o papel das instituições políticas no desenvolvimento de uma nação. Logo, é possível interpretar que instituições políticas compreendem organizações, atos normativos e princípios que regem um Estado ou vários estados (no caso de instituições políticas internacionais).

Em todas as áreas de uma sociedade grupos de interesse são capazes de influenciar tomadores de decisões para agir ou deixar de agir de forma a tentar garantir que seus interesses sejam mantidos ou alcançados. A literatura sobre políticas públicas apresenta diversas teorias para a compreensão desse fenômeno, mas são uníssonas em destacar a relevância das instituições para a definição da Agenda política. Isso porque a Agenda, segundo Secchi (2013, p. 46), é um conjunto de problemas ou temas entendidos como relevantes, podendo ser classificada, conforme Cobb e Elder (1983) em agenda política ou sistêmica e agenda formal ou institucional. A primeira é o conjunto de problemas ou temas que a comunidade política considera como merecedor de intervenção pública, enquanto a última elenca os problemas ou temas que o poder público já decidiu enfrentar.

O caso da comunicação científica não é exceção nesse contexto. Isso porque seus stakeholders, nomeadamente autores e suas organizações, editores, profissionais da informação e da tecnologia da informação e agências de fomento constituem grupos de interesse que são capazes de influenciar tomadores de decisão para alcançar seus objetivos. Destaquem-se, nessa discussão, as editoras, que atuam junto a autoridades responsáveis por definir políticas públicas que garantam o lucro obtido com a venda de periódicos científicos. Esse modelo de atuação das editoras provocou o surgimento, há pouco mais de dez anos, do Movimento do Acesso Aberto na comunicação científica. O Movimento fundamenta-se na noção de que o conhecimento científico, resultado, principalmente, de investimentos públicos, deve estar acessível a todos. De fato, a noção de que conhecimento científico é, por natureza, algo comum a todos constitui o moto do movimento. O Movimento, portanto, visa ao maior benefício da disseminação de resultados de pesquisa para a comunidade acadêmica, em particular, e para a sociedade como um todo.

Essa situação, que confronta claramente os interesses de editoras e autores - detentores dos direitos autorais de obras publicadas- constitui, portanto, o foco da discussão. Isso porque entende-se que o conflito entre direito autoral e acesso aberto à informação científica pode ser regulamentado por políticas públicas destinadas ao fomento da disseminação do conhecimento produzido em instituições de pesquisa. Para tanto, o papel das instituições políticas envolvidas no contexto da educação, da pesquisa e da propriedade intelectual é importante para determinar até que ponto os interesses diversos podem ser harmonizados no contexto social ora estudado.

\section{Metodologia do estudo}

A pesquisa de mestrado para a qual se construiu a presente fundamentação teórica constitui um trabalho analítico descritivo com abordagem qualitativa. O estudo foi conduzido, inicialmente, por meio de análise da literatura especializada nos tópicos que constituem seu aporte teórico. Adicionalmente, o estudo identificará, por meio de levantamento baseado em análise documental, legal e entrevistas semiestruturadas em profundidade, a percepção e as experiências dos gestores de repositórios sobre a questão do direito autoral no contexto do acesso aberto. Em seguida, descreverá os elementos necessários e uma proposta de política para universidades. 
A construção da fundamentação teórica do estudo, portanto, objeto de objetivo específico do estudo, que é descrever questões que fundamentam a discussão sobre o direito autoral no contexto do acesso aberto à literatura cientifica, compreendeu:

1. Identificação de fontes de informação relevantes (publicações científicas e legais);

2. Pesquisa bibliográfica e documental, por meio de levantamento da literatura e da legislação;

3. Condensação e interpretação dos textos;

4. Descrição dos aspectos identificados pela análise da literatura, configurando o estado da arte sobre o assunto pesquisado;

São abordados, portanto, no presente texto, os conceitos que constituem a base teórica para o tema estudado, e que nortearam a condução do estudo como referencial teórico adotado. Esse referencial está refletido na própria estruturação do trabalho, como resultado da análise da literatura relevante sobre os temas abordados. Dessa maneira, foi possível a identificação de tendências no que diz respeito ao direito autoral, ao acesso aberto à informação científica e políticas públicas. Os resultados obtidos desses levantamentos e leituras estão apresentados nas seções a seguir.

\section{Instituições na política pública}

Países de língua latina apresentam dificuldades com relação a alguns termos das ciências políticas. Já os países de língua inglesa diferenciam facilmente os termos politics e policy. Neste trabalho será adotado o conceito de policy que segundo Secchi $(2013$, p. 1) é a política concreta que guarda relação com orientação para decisões e ações. Politics, diferentemente de policy é conceituado por Bobbio (2002, p.49) como "atividade humana ligada à obtenção e manutenção dos recursos necessários para o exercício do poder sobre homem". 0 autor exemplifica o conceito com a seguinte frase: "a política de Brasília está distante das necessidades do povo". Como esse estudo trata de ações concretas, preferiu-se conceituar as traduções dos termos para esclarecer o que será abordado, isto é, policy.

O termo política pública está vinculado, portanto, a este conceito de política, na medida em que trata do conteúdo das decisões políticas, do processo de construção e da atuação dessas decisões. A política pública é uma "orientação à atividade ou passividade de alguém" conforme observa Secchi (2013, p.2). Outra questão que chama a atenção é que a política pública trata de um problema público, e não se confunde com políticas governamentais, as quais apenas compõem um subgrupo das políticas públicas, que atualmente recebe mais atenção na literatura da área. É importante ressaltar que a abordagem estadística ou estadocêntrica (statecenteredpolicy-making) considera que as políticas públicas são emanadas apenas de um ator estatal, confundindo-as, assim, com políticas governamentais. Contudo, neste trabalho entendem-se as organizações privadas, organizações não governamentais, organismos multilaterais e rede de políticas públicas (policy networks) como parte das políticas públicas, juntamente com os atores estatais. Essa interpretação coaduna-se com a abordagem multicêntrica ou policêntrica defendida por Rhodes (1997 apud SECCHI, 2013, p. 3) e Hajer (2003, p.190). A figura 1 ilustra essa abordagem.

Figura 1 - Políticas públicas e políticas governamentais

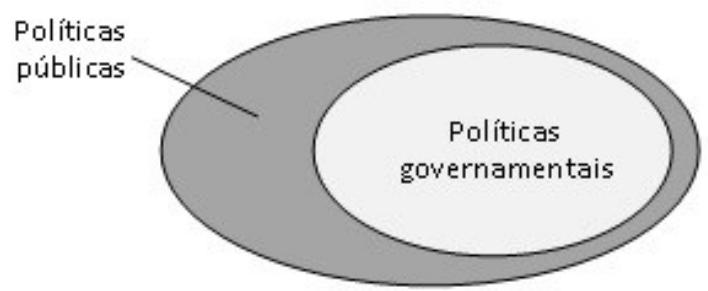

Fonte: Secchi $(2013$, p. 5) 
Ao longo do tempo muitos estudiosos buscaram compreender o processo de construção de uma política. Esses estudos resultaram em diferentes teorias acerca do processo de formação de uma política pública. A seguir, são apresentadas seis abordagens de autores relevantes para a discussão dessas teorias.

Primeiramente, Acemoglu e Robinson (2012) esclarecem os motivos que levam alguns países ao êxito econômico e outros à pobreza de sua população por meio das características de suas instituições. Seu argumento é que a principal causa dos diferentes graus de desenvolvimento econômico das nações não é a economia em si, mas a política. Os sistemas políticos adotados pelas diferentes nações são decisivos para a determinação de seu sucesso ou fracasso econômico. Isso porque as instituições atuantes no sistema favorecem ou prejudicam a atividade econômica do país. Os países mais desenvolvidos economicamente apresentam instituições políticas que estimulam a produção agrícola e industrial além de favorecerem a inovação tecnológica e científica. No caso dos países menos desenvolvidos economicamente, as instituições políticas, que devem fomentar a atividade econômica, na verdade perpetuam um sistema que favorece aqueles que controlam os fatores reais de poder e aumentam cada vez mais a desigualdade social de sua população.

Em segundo lugar, Zahariadis (2007) defende a teoria dos fluxos múltiplos nos processos de criação das políticas públicas. No bojo dessa teoria, são identificados três fluxos dentro do sistema político, quais sejam: problemas, políticas públicas (policies) e política (politics). Todas elas são independentes e possuem suas próprias particularidades. Contudo, as instituições são capazes de juntar esses três fluxos em momentos críticos, quando surge a oportunidade, para potencializar as chances de que certa política pública seja criada e adotada pelo Estado. A teoria dos fluxos múltiplos se assemelha à Teoria dos Sistemas, por considerar a análise da tomada de decisão num contexto sistêmico (resultante de diversos fatores), semelhante à Teoria do Caos. $\mathrm{O}$ resultado da atuação dos múltiplos fatores no processo não é determinado, ou seja, não pode ser previsto.

Em terceiro lugar, deve-se considerar também o modelo apresentado por Kingdon (2011), que considera as organizações governamentais como "anarquias organizadas", onde a ambiguidade predomina e são caracterizadas por três propriedades. A primeira compreende a participação dinâmica, onde a atuação dos agentes, governamentais ou não, é "fluida" e as mudanças de pensamentos são frequentes e variam a cada decisão tomada. A segunda diz respeito a preferências problemáticas, em que os tomadores de decisão não são claros no que querem e em seus objetivos. Finalmente, há a tecnologia incerta, que éuma forma desconhecida de como as informações e insumos apresentados são transformados ao longo do processo decisório.

Como quarta abordagem, o estudo de Bonafont (2004) sobre Redes de Políticas Públicas defende que o processo de criação e desenvolvimento de uma política pública não se limita apenas à mobilização de grupos sociais. Mais que isso, leva em conta a forma em que tais grupos se institucionalizam nas relações de poder entres os atores ao longo do tempo, enfatizando a autonomia das instituições na vida política. Dessa forma, as instituições tem papel de ator imprescindível para o estudo e o entendimento dos processos políticos, visto que é possível explicar todo o processo a partir da ideia de que é o resultado da atuação de indivíduos racionais em prol de interesses particulares. As instituições tem autonomia e defendem interesses e ideias que caracterizam o coletivo que representam, dispondo de mecanismos para influenciar em um nível mais amplo do que os indivíduos.

Em quinto lugar, o surgimento da Análise de Redes de Políticas Públicas (Policy Network) tem a finalidade de identificar diversas maneiras de intermediação de interesses entre setores da sociedade de um país ao longo do tempo. É, de forma geral, utilizada para avaliar os aspectos de relacionamentos institucionais envolvidos no processo de desenvolvimento de políticas públicas. Sua definição é um conjunto de relações relativamente estáveis entre atores públicos e privados que interagem por meio de uma estrutura hierárquica e interdependente, para alcançar objetivos comuns referentes à política. Essa abordagem busca elucidar os motivos pelos quais os diversos países adotam estratégias diferentes para os mesmos problemas, apesar da homogeneização que organismos internacionais e blocos econômicos proporcionam, num contexto global. Também procura explicar o processo de elaboração de políticas públicas como consequência de um processo de troca e negociação entre entes públicos e privados, interagindo com o objetivo de intercambiar informações e recursos num marco institucional concreto. A constante interação entre os entes públicos e privados possui destaque nessa abordagem, ressaltando a "interdependência" e a cooperação necessária entre esses agentes para a gestão pública.

Além das cinco relevantes teorias supramencionadas, é importante destacar o trabalho de Wableet al (2011) sobre o Sistema de Coalizões de Advocacia (Advocacy Coalition Framework - ACF). Tal teoria estuda o processo de políticas públicas considerando os subsistemas de política como foco da análise, em perspectivas 
de longo prazo, em que o crescente número de atores envolvidos permite que estes se agrupem em coalizões e que o desenho final das políticas reflita os anseios das coalizões eventualmente formadas. O Sistema em questão possui três grandes linhas teóricas de análise. A primeira linha refere-se à formação de coalizões, sua organização e sua estabilidade ao longo do tempo. Já a segunda linha refere-se ao aprendizado orientado para a política pública. Finalmente, a terceira linha diz respeito à mudança em políticas públicas, mais especificamente o papel das coalizões nas mudanças políticas. A primeira e a terceira linhas teóricas são bastante exploradas pela literatura da Ciência Política, enquanto que a segunda linha ainda carece de maior atenção por parte dos estudiosos.

A partir da teoria da ACF, cujo enfoque principal é a formação de coalizões, é possível analisar o papel que o Movimento do Acesso Aberto desempenha no contexto do Direito Autoral na comunicação científica. Isso porque o movimento representa a coalizão institucional de diversos atores particulares que buscam alterar o status quo que vigora atualmente. Por esta razão, o estudo de mestrado para o qual se desenvolveu a fundamentação teórica objeto deste artigo, adota a teoria da ACF como modelo. Como resultado, o estudo aponta para a necessidade de introdução de uma nova coalizão no cenário existente, alterando o somatório de forças que atuam sobre os processos políticos que definem as políticas públicas para as áreas da comunicação científica e do Direito Autoral.

\section{Direito Autoral}

O direito de autor é uma conseqüência do processo tecnológico dos meios de comunicação. Faz-se necessário, no entanto, discutir os prolegômenos da questão, para melhor entendimento.

$\mathrm{Na}$ antiguidade esse direito era desconhecido

[...] mesmo na Grécia antiga, berço das artes e capital intelecto; ou ainda Roma, criadora do Direito, no sistema precisamente denominado romanístico, pouco ou nada sabiam sobre meios de proteger os criadores intelectuais da utilização indevida, do plágio, da falsificação de suas obras (ARAÚJO, 1999, p. 10)

Com o surgimento da imprensa, intensificaram-se as discussões acerca dessa questão, em virtude da possibilidade de perda do controle dos autores de trabalhos escritos sobre a reprodução das suas obras, devido à facilidade de multiplicação das cópias impressas. Portanto, as primeiras manifestações dessa evolução dirigiam-se mais aos editores, com o estabelecimento de regime de privilégios, concedidos pelos monarcas para a exploração econômica das obras intelectuais. Segundo Cabral (2004, p.5) "o autor no caso não tinha qualquer vantagem econômica". O sistema beneficiava impressores e vendedores chamados stationers.

Desde fins do século XVII foi tomando corpo um forte movimento de opinião favorável à liberdade de imprensa e aos direitos dos autores. Estes, por sua vez, se consideravam protegidos pela commonlow e contrários à StationerCompany, de Londres, poderosa corporação empenhada em defender os interesses dos impressores e livreiros que haviam recebido o privilégio de censurar as obras que publicassem (CABRAL, 1993, p. 5).

Foi, na verdade, na época da Revolução Francesa - fins do século XVIII-, que a propagação de idéias novas fez com que os autores se conscientizassem da importância da sua produção artística (ARAÚJO, 2004). Surgiu, então, na Inglaterra a lei conhecida como o "Estatuto da Rainha Ana", que teve a pretensão de inverter a valorização, até então, dada ao editor, para garantir o direito do criador da obra e não daquele que a reproduzia. De acordo com Araújo (2004, p.5) “... agora os stationaries - impressores e livreiros - poderiam continuar imprimindo suas obras, mas deveriam adquiri-las dos por meio de um contrato especial." O impacto dessas ações levou os países a iniciarem uma série de ações e tomarem medidas próprias para lidar com a questão. Além disso, o tema tornou-se de suma importância, provocando a realização de convenção específica para sua discussão e tomada de decisão a respeito.

Com o Estatuto da Rainha Ana, muitos países, décimo primeiro país a fazê-lo, editaram leis protegendo os direitos de autor. Entretanto, as nações se recusavam a reconhecer os direitos de autor de trabalhos de estrangeiros. Para tratar dessa e de outras questões, foi realizada, em 1886, na cidade de Berna, Suíça, a Convenção da União de Berna (CUB), terceira conferência diplomática sobre direitos autorais, que estabeleceu o reconhecimento do direito de autor entre nações soberanas.

É o mais antigo tratado internacional em vigor e aplicado. Sofreu várias revisões que tiveram por finalidade atualizá-lo em face de novas realidades sem, contudo, alterar sua espinha dorsal que é a defesa e proteção dos direitos patrimoniais e morais do autor. Sua última 
revisão data de 24 de julho de 1971, com emendas de 28 de setembro de 1979, que é o documento hoje em vigor. (CABRAL, 2003, p. 21)

A Convenção de Berna tem sido modelo para as legislações sobre direitos autorais em vários países do mundo, inclusive no Brasil. A Convenção foi revista em Paris (1896) e Berlim (1908), completada em Berna (1914), revista em Roma (1928), Bruxelas (1948), Estocolmo (1967) e Paris (1971), e emendada em 1979.

Para mediar à questão da propriedade intelectual no mundo, foi criada em 1967 a Organização Mundial da Propriedade Intelectual (World Intellectual Property Organization - WIPO), ligada ao sistema Nações Unidas e com sede em Genebra, Suíça. Sua missão é proporcionar um ambiente para a discussão e informação sobre políticas e serviços referentes à propriedade intelectual no mundo, na tentativa de que seja alcançado um sistema mundial equilibrado que promova a inovação e que beneficie a todo o planeta. A WIPO é responsável por administrar a Convenção de Berna e, segundo informação extraída do seu site oficial (http://www.wipo.int/about-wipo/en/index.html), a Convenção já conta com 165 países signatários.

Outra norma internacional que ganhou relevância por rediscutir alguns dispositivos da Convenção supra e por inovar em outros aspectos como a regulamentação de software diante do direito de propriedade intelectual foi o Agreement on Trade-Related Aspects of Intellectual Property Rights (TRIP's). O TRIP's é um tratado internacional, integrante do conjunto de acordos assinados em 1994 que encerrou a Rodada Uruguai e criou a Organização Mundial do Comércio. O foco da contribuição do TRIP's abrange três questões.

a primeira contendo disposições gerais e princípios básicos, tais como tratamento nacional e uma cláusula de nação mais favorecida; a segunda discorrendo sobre cada um dos direitos, em sucessão (copyright, marcas, apelações geográficas, desenhos industriais, patentes etc.); e a terceira indicando as obrigações dos membros no sentido de estabelecer procedimentos e remédios no contexto de suas legislações nacionais para assegurar que os direitos sejam efetivamente protegidos e respeitados. (BARBOSA; BARBOSA, 2010, p. 113)

O acordo TRIP's se constitui como um importante instrumento de proteção intelectual em nível internacional. Contudo, segundo Rocha (2010, p. 205), os países desenvolvidos, descontentes com algumas disposições do Acordo, forçam os países menos desenvolvidos a assinarem tratados que disponham sobre um nível de proteção superior à estabelecida no TRIP's que seria por exemplo o TRIP's Plus no qual o Brasil é signatário.

Os professores Pimentel e Barral (2007, p. 26) explicam que "a corrente de Sherwood postula que os países subdesenvolvidos devem aumentar a proteção à propriedade intelectual para obterem benefícios substanciais, como investimentos, tecnologia e, em geral, um crescimento econômico do país". Entretanto, os autores acrescentam, ainda, que esse tipo de estímulo é um sofisma. Isso porque a efetiva transferência de tecnologia é o único meio capaz de gerar desenvolvimento, se conjugada com políticas de investimentos em conhecimento e novas tecnologias.

Ainda nas palavras de Rocha (2007, p. 207) é de interesse dos países desenvolvidos que os períodos de proteção e exclusividades para o compartilhamento da propriedade intelectual sejam cada vez maiores, pois dessa forma os países destituídos de tecnologia ficam por mais tempo dependentes. Para Sen $(2000$, p.18)

[...] A despeito de aumentos sem precedentes na opulência global, o mundo atual nega liberdades elementares a um grande número de pessoas - talvez até mesmo a maioria. Às vezes a ausência de liberdades substantivas relaciona-se diretamente com a pobreza econômica, que rouba das pessoas a liberdade de saciar a fome, de obter uma nutrição satisfatória ou remédios para doenças tratáveis, a oportunidade de vestir-se ou morar de modo apropriado, de ter acesso a água tratada ou saneamento básico [...]

A Coréia do Sul pode ser tratada como exemplo para a citação de Sen (2000), pois nos últimos quarenta anos o governo sul-coreano iniciou a implantação de um programa de desenvolvimento de tecnologia em todos os setores produtivos. Segundo o professor Kim da Universidade de Seul, o programa iniciou-se com o incentivo à absorção de tecnologia por meios indiretos, como a imitação e a engenharia reversa que consiste em desmontar o produto para se descobrir como se chegou à invenção final. (KIM, 2003, p.4). Com o intuito de diminuir a dependência tecnológica, os investimentos em pesquisa e desenvolvimento (P\&D) aumentaram substancialmente ano após ano. Com isso, mais de trinta e nove multinacionais instalaram centros de P\&D no país, fazendo com que, atualmente, a Coréia esteja dentre os países que mais registram patentes no mundo.

Kim (2003, p.5) ensina quatro lições sobre o caso de desenvolvimento da Coréia. A primeira é que padrões elevados de proteção da propriedade intelectual podem dificultar ao invés de facilitar a transferência de 
tecnologia. A segunda lição é que, após acumular conhecimentos deve-se investir em estrutura para o desenvolvimento de ciência e tecnologia. Depois são necessárias políticas de adequação e proteção de propriedade intelectual nos níveis exigidos pelos investidores internacionais. Por último, o país em desenvolvimento deve participar dos sistemas multilaterais de proteção da propriedade intelectual.

Diferentemente da Coréia do Sul, o Brasil não adotou medidas semelhantes. Vários fatores, inclusive políticos, fizeram com que o país adotasse uma estratégia voltada para a exportação de matérias-primas, gêneros agrícolas e produtos com pouca complexidade industrial e baixo valor tecnológico agregado. (ROCHA, 2010, p. 211). Atualmente, está em vigor no Brasil a Lei de Direitos Autorais - LDA (Lei $n^{\circ}$ 9.610, de 19 de fevereiro de 1998) que, segundo Santos (2009, p.21) "[...] apresenta uma série de dispositivos que convergem para a manutenção do poder do autor ou de seus representantes em proibir ou decidir quem utilizará e como serão exploradas economicamente suas criações".

Comparada com as demais legislações sobre direitos autorais no mundo, a LDA pode ser considerada mais restritiva no que se refere ao acesso às informações. De acordo com o artista e ex-Ministro de Estado da Cultura, Sr. Gilberto Gil, esse fato não condiz com a realidade socioeconômica do país "É importante que através [sic] das leis, dos processos de regulação, se mantenha o equilíbrio, o mais justo possível, entre o direito dos autores, dos criadores, enfim, artistas, criadores intelectuais de um modo geral, e do outro lado o interesse público".

A abordagem TRIP's, conforme Barbosa e Barbosa (2010, p. 112), resultou no endosso repetido, pelo Ministério da Cultura, na difusão de trabalhos de livre acesso além de planejar a emissão de uma diretiva pública no tocante a direitos autorais. Um dos objetivos dessa diretiva foi promover uma consulta pública a respeito da atual Legislação de Direitos Autorais - LDA (Lei n. 9.610/98) que será melhor abordada na próxima seção.

Importante, ainda, destacar que a distribuição dos direitos autorais relativos a obras de empregados era regulada pelo art. 36 da Lei. 5.988/73 (lei anterior à Lei 9.610/98), e estabelecia a partilha equitativa do Direito do Autor entre empregado e empregador. Entretanto, a Lei n. 9.610/98 não regulou a matéria e por isso deixou um vácuo normativo. Cabral (1998, p. 135) afirma que, em decorrência da lei 9.610/98 o "Direito Autoral pertence inteiramente ao autor, o que exige, desde logo, contrato especial. E nesses casos, o ajuste que a realidade indica é o contrato de cessão de direitos, dentro do que estabelece a Lei n. 9.610/98".

No entanto, Leite $(2009$, p.77) pondera que as regras que permeiam os direitos de autor não podem ser absolutas a ponto de privilegiar apenas os interesses dos titulares da obra, nem tão relativas no sentido de considerar apenas os interesses da sociedade. A fim de equilibrar o direito do autor e o direito de acesso, sem a necessidade da cessão dos direitos autorais como afirmou Cabral, surgiu a doutrina do fairuse e projetos colaborativos, como o copyleft e o Creative Commons.

O fair use ou "uso justo" permite o acesso a obras sem a necessidade de adquiri-las, como o uso para ensino e pesquisa. O Congresso Norte-Americano listou os quatro fatores que devem ser considerados na análise do caso concreto. Primeiro, o propósito e espécie de utilização (comercial, educacional). Segundo, deve-se analisar a natureza da obra intelectual protegida. Em terceiro lugar, é necessário verificar a quantidade e proporcionalidade do trabalho copiado com relação ao todo. E, por fim, o efeito do uso no mercado da obra originária. (PINHEIRO, 2010, p. 97)

A doutrina do fair use, atualmente, encontra aplicabilidade apenas no sistema common law, como o norteamericano, que parte da ausência de um regramento específico. Isso não ocorre no sistema europeu, no qual as limitações à legislação são previstas em um rol taxativo de condutas, como ocorre no Brasil. O art. 46 da LDA foi, de fato, muito pontual quanto ao uso permitido de obras intelectuais.

O copyleft surgiu como resposta ao copyright. Ressalta-se, aqui, que o copyright difere do direito de autor, tendo em vista que os países anglo-saxões, mais especificadamente os EUA, preservam a tradição do common law e veem o direito autoral como algo objetivo e/ou direito de propriedade, portanto direito exclusivo de cópia de um trabalho. Já a tradição francesa ressalta aspectos pessoais da criação e não só como um direito de cópia exclusiva. Nos países influenciados pelo droit d'auter (como Brasil e a maioria da America Latina) os padrões básicos legais são direcionados à proteção da personalidade individual do autor e não à de seus interesses de propriedade.

O copyleft é uma licença que se convencionou chamar de pública por estar disponível a qualquer pessoa que queira adotá-la. Ela utiliza o sistema do copyright para garantir "que todos que recebam sua versão da obra 
possam usar, modificar e distribuir tanto a obra original quanto as suas versões derivadas". (SANTOS, 2009, p. 137)

Santos (p. 138) esclarece, ainda, que a licença copyleft teve sua origem no movimento do software livre, que é baseado no princípio do compartilhamento de conhecimento e na inteligência coletiva conectada na rede mundial de computadores. Consiste em um mecanismo jurídico (contrato) que visa a garantir aos titulares de propriedade intelectual que possam licenciar o uso de suas obras além dos limites da lei, mas, ainda assim, amparados por ela. Dessa forma, permite que terceiros utilizem as obras nos termos da licença pública outorgada.

É o caso do projeto Creative Commons, que se originou a partir de reflexões filosóficas elaboradas pelos professores Lawrence Lessing da Universidade de Stanford e James Boyle da Duke Law School. A inspiração do projeto, segundo os próprios autores, foi na obra de Richard Stallman e nos trabalhos produzidos pela Fundação Software Livre - Free Software Foundation, as quais deram origem ao copyleft (PONTES, 2009, p. 96). Stallman criou o sistema de licenças públicas, o General Public License (GPL), por acreditar que os programas de computador não poderiam estar sujeitos às regras usuais do comércio, o que seria um "obstáculo intransponível ao desenvolvimento da comunidade informática como um todo".

A Fundação Creative Commons oferece um conjunto de licenças virtuais como meio de contratação das obras científicas, artísticas e literárias, instituídas sob duas formas: as licenças denominadas "common deed" e as "legalcode". A common deed foi criada como uma linguagem "humana" que significa uma versão "humanamente compreensível", ou ainda, um formato que todos podem entender sem a presença de um especialista jurídico. Essa versão é simplificada por desenhos que representam símbolos. A outra versão intitulada de "legal code" são os contratos jurídicos de fato.

Cabe ressaltar, aqui, que a transmissão dos direitos autorais pode ser feita por meio de cessão, concessão e licença. A cessão de direitos transfere a titularidade patrimonial e, com isso, transfere todos os direitos patrimoniais. Já a concessão transfere apenas parte específica dos direitos patrimoniais tornando o concessionário titular dos direitos transferidos. A licença é a forma que tem sido considerada a mais prudente e necessária para o avanço da filosofia aberta, pois ela apenas autoriza ao licenciado a utilização da obra da forma que foi acordada com o licenciante. Logo, a licença consiste na autorização e não na transferência da titularidade dos direitos autorais, ou seja, o autor permanece com os seus direitos patrimoniais sob a obra.

Apesar de a licença Creative Commons assumir um papel importante na revolução pacífica por meio do próprio direito é também alvo de critica por alguns juristas como Pimenta (2004, p.387). Para o autor, os contratos de licença de direitos autorais, principalmente aqueles que visam à utilização de obras na internet, não devem prescindir de regras que orientam a transmissão das obras pela doutrina tradicional como, por exemplo: localidade do cumprimento da licença, rescisão, direito aplicável, eleição de foro etc. Outra crítica é com relação à falta de responsabilidade da Fundação Creative Commons com relação aos contratos. Maranola $(2005$, p. 72) afirma que o resumo da licença publicado no site não constitui propriamente uma licença, já que está escrito tratar-se de um sumário para leigos da licença jurídica e logo em seguida aparece um termo de exoneração de responsabilidade. Diz, ainda, estranhar o modo como a Creative Commons tem feito constar no corpo das licenças que não responde pelas informações disponibilizadas, exonerando-se de qualquer responsabilidade por danos resultantes de seu uso. No entanto, como observa Maranola (2005, p. 72), a própria Creative Commons sugere e oferece os modelos de contrato de licença para uso público.

É claro que não é possível comparar a Fundação Creative Commons com um escritório de advocacia, como afirma Pontes (2005, p.119). A instituição não presta serviços jurídicos e não é parte anuente nem interveniente em nenhum dos contratos. Mas, ainda assim, ela contribui indiscutivelmente para o alcance dos seus objetivos, sendo, o principal, a democratização do acesso à informação.

Assim como o Creative Commons, outros movimentos surgiram sob a influência do copyleft. São citados como exemplo disso o free art licence, o open audio licence, o Open Cola, a Wikipédia. Como fruto dessa filosofia de acesso aberto também surgiu o Open Journal System, criado por John Willinsky na Universidade de British Columbia, uma plataforma para gerenciar a criação e gestão de periódicos, no contexto do acesso aberto. Esses diferentes movimentos aconteceram porque o copyleft não convergiu as opiniões para um mesmo sentido. Segundo Marandola (2005, p.21) o copyleft tem "várias ideologias e finalidades".

A falta de foco do copyleft pode ter contribuído para o fracasso da maioria dos movimentos derivados dessa filosofia. Contudo, segundo Pontes (2009, p.105), um dos motivos do movimento Open Access ter adquirido 
importância e significado foi por difundir conhecimento no âmbito científico e acadêmico, assunto que será estudado na próxima seção.

\section{Acesso aberto na comunicação científica e os direitos autorais}

À época do auge da crise dos periódicos, que se deu quando da tomada de consciência sobre a possibilidade de meios alternativos para disseminação da ciência, Stevan Harnard publicou um artigo chamado Scholary Skywriting and the Prepublication Continuum of Scientific Inquiry. Segundo o autor, a "disseminação da palavra escrita na 'Era Pós-Galaxia de Gutemberg' seria como escrever no céu, para todo mundo ver e adicionar seus comentários como se fosse grafite nos banheiros públicos” (HARNAD, 1998, p. 342).

No meio acadêmico, o movimento em defesa do livre acesso aos trabalhos científicos ficou conhecido como Movimento do Acesso Aberto, que pode ser definido, segundo as declarações de Berlim, Bethesda e Budapeste, como acesso à literatura que é digital, online, livre de custos, e livre de restrições desnecessárias de copyright e licenças de uso. Portanto, deve remover tanto barreiras de custo quanto de autorização de uso. Ortellado (2006, p.5) acrescenta a disposição livre e pública de um texto, de forma a permitir a qualquer um a leitura, cópia, impressão, distribuição e, quando for o caso, download, busca ou o link com o seu conteúdo completo, assim como a indexação ou o uso para qualquer fim não comercial.

Suber, na sua página na web ${ }^{1}$, introduziu o acesso aberto como

A literatura de acesso aberto é digital, online, gratuita e se exonera da maioria dasrestrições dos direitos autorais e das licenças, o que torna isso possível é a internet e o conhecimento do autor ou do titular do copyright. Na maioria dos campos de conhecimento, as revistas especializadas não pagam aos autores, os quais, portanto, podem autorizar o acesso aberto sem que ele repercuta em suas receitas. Assim, os cientistas e os acadêmicos se encontram em uma situação muito diferente da maioria de músicos e cineastas, e a polêmica a envolver o acesso aberto para a música e para o cinema não pode transferir-se para a literatura científica. (tradução nossa)

No campo da comunicação científica, ainda resiste, exclusivamente entre editoras comerciais, a ideia de que o Acesso Aberto acabaria com a lucratividade das obras científicas, o que poderia comprometer a produção. Essa postura, no entanto, provoca uma queda de braço entre autores e editores, visto que os primeiros estão interessados, de fato, na disseminação de seus resultados e no reconhecimento de seus trabalhos, não em possíveis lucros. O direito autoral se apresenta como uma principal causa de enfrentamentos e discussões. Isso porque é nele que as editoras se apóiam para defender seus pontos de vista, por meio de suas políticas próprias de proteção do autor e da integridade do texto. É nele, também, que autores devem se basear para lutar por ter seus trabalhos acessíveis. De fato, o modelo tradicional de publicação fere os princípios do Acesso Aberto, visto que, ao tomar posse dos direitos patrimoniais da obra, cedidos pelo autor, o editor se torna titular dos conteúdos, passando a cobrar pelo seu acesso e uso. O modelo que se baseia na filosofia do acesso aberto luta por, além de resguardar esses direitos ao autor, ampliar o máximo possível o acesso e uso de sua obra.

Para tanto, o Movimento do Acesso Aberto segue duas vias: a dourada e a verde. A dourada diz respeito à revista científica que dá acesso aberto a seus conteúdos, por meio de diversificados modelos de negócios. A via verde dispõe sobre os arquivos abertos, em especial os repositórios de acesso aberto, em que são depositadas cópias das publicações dos pesquisadores. Assim, o movimento surgiu para solucionar problemas com os custos abusivos das editoras. Mais que isso, surgiu também para responder questões sobre a necessidade das bibliotecas das instituições dos autores terem que comprar sua produção de volta e autores terem que ceder todos os direitos ao editor, necessitando de autorização para acessar e usar seus próprios trabalhos. (FRIEND, 2004, p.1)

O Movimento do Acesso Aberto permitiu, de certo modo, que autores e suas instituições participem do mercado distribuidor de conteúdos digitais, competindo, assim, com as editoras. Afinal, esses atores do sistema de comunicação da ciência passaram, muitas vezes em colaboração com gestores de repositórios, a disseminar a própria produção intelectual, interferindo na exclusividade das editoras. Nesse contexto, Hurd (2004, p.13) apresentou um modelo que ilustra o processo de comunicação com mudanças introduzidas pelo movimento do acesso aberto. Observa-se, contudo, a inexistência de etapas do processo que se tornaram cruciais no contexto atual, nomeadamente, negociações entre autores e editores, mediação por gestores de repositórios (em sua maioria, bibliotecários), assim como adoção e observação de novos modelos de negócios e novos modelos de

$1 \mathrm{http}: / /$ legacy.earlham.edu/ peters/hometoc.htm 
licenças públicas de acesso e uso. Isso porque o Movimento do Acesso Aberto alertou a comunidade científica para a relevância da questão dos direitos autorais. Adaptado de Hurd (2004), o modelo do processo de comunicação científica que introduz essas questões é ilustrado na figura 2.

Figura 2: Direitos autorais na comunicação científica

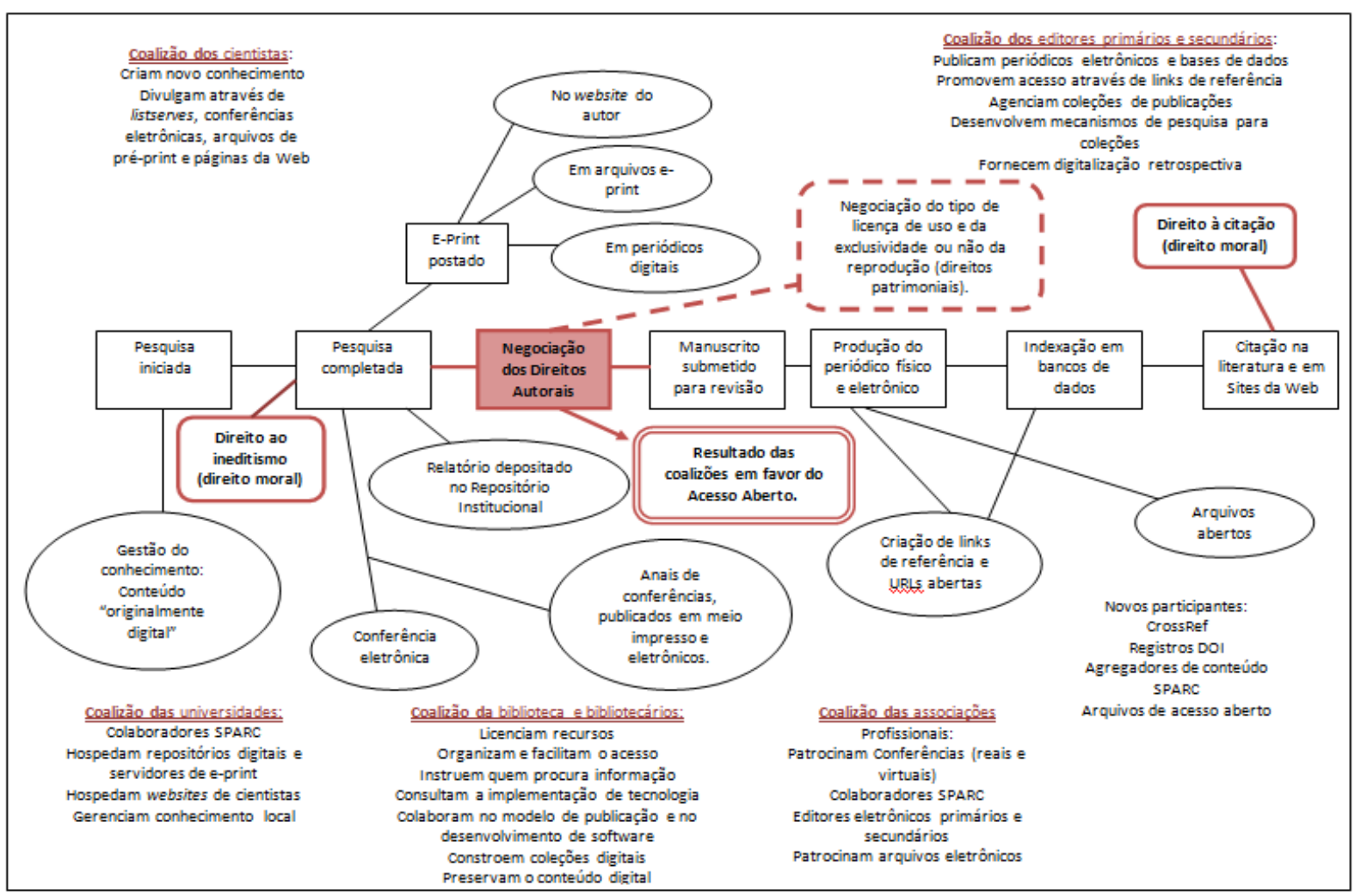

Fonte: Traduzido e adaptado de Hurd (2004).

Como é possível notar, a figura 2 ilustra modelo adaptado de Hurd (2004), a qual, por sua vez, adaptou modelo de comunicação científica de Garvey e Griffith (1979), em que incluiu a comunicação científica em Acesso Aberto ao modelo tradicional dos autores. No presente trabalho, acrescentam-se ao modelo de Hurd as etapas relacionadas ao direito de autor. Essas inclusões refletem mudanças que provocaram a necessidade, por parte dos principais atores do processo de comunicação científica - autores e suas instituições, editores, associações científicas e agências de fomento- de se organizar em grupos de interesse. Quando um grupo de interesse atinge certo nível de organização é considerado um sujeito organizado, a que Bobbio (1998, p. 77$)$ nomeia de coalizão.

São várias as coalizões de interesse que interferem diretamente no processo de comunicação científica, mesmo que não haja um interesse direto por parte de algumas. Isso porque instituições de Direitos Autorais consideram tanto a obra científica como a artística e a literária como objetos de proteção. Observe-se que são obras que possuem características distintas entre si, principalmente com relação à finalidade, embora sejam, na verdade, obras intelectuais. Mas essa aproximação legal faz com que, equivocadamente, grupos de interesse, tais como músicos, artistas cênicos e outros, discutam diretamente a questão dos Direitos Autorais na Comunicação Científica.

É importante observar que o cenário marcado pela inclusão de obras científicas, artísticas e literárias no mesmo texto legal acontece na maioria dos países signatários da Convenção de Berna, inclusive o Brasil. O que difere o tratamento dado aos direitos autorais além dos dispositivos peculiares a cada nação é o grau de restrição que a legislação impõe aos cidadãos. Portanto, mesmo que a Convenção de Berna estabeleça critérios mínimos, é possível restringir ainda mais no âmbito de cada país. O que vai dosar o grau de restrição são as coalizões que formam a Agenda de cada país. Na seção a seguir são apresentados resultados da análise conduzida nos registros de consulta pública realizada no Brasil para discutir a revisão da atual legislação de direitos autorais no país. 


\section{Relevância das coalizões no direito autoral: a realidade brasileira atual}

Foi possível mapear as coalizões de interesse a partir de uma consulta pública que o Ministério da Cultura brasileiro fez sobre um anteprojeto de lei para revisar a Lei de Diretos Autorais. Conforme noticiado pelo próprio Ministério, a participação foi ampla. Ao todo, foram recebidas 8.431 manifestações durante a Consulta Pública, sendo 7.863 via Internet e 568 por documentos impressos ou e-mails. Deste montante, $58 \%$ foram de contribuições para o aperfeiçoamento do texto e $42 \%$ de posicionamentos sobre dispositivos apresentados no anteprojeto, sem propostas concretas.

A análise dos documentos obtidos por meio da consulta, orientada pela teoria da ACF com vistas a identificar grupos de interesse envolvidos no tema, permitiu mapear a visão de quatro entidades que se manifestaram. Conhecer seus argumentos contribuiu para identificação e descrição do cenário brasileiro diante dos direitos autorais na comunicação científica. São apresentados a seguir os argumentos dos quatro grupos de interesse, os dois primeiros contrários e os dois últimos a favor do anteprojeto.

\section{Argumentos do ECAD}

Uma das manifestações mais veementes contra as alterações propostas à Lei 9.610/1998 é a do Escritório Central de Arrecadação e Distribuição (ECAD), que representa diversas associações de proteção ao direito de autor- compositores de música - e entidades diretamente interessadas no tema. De acordo com o Escritório, os direitos constitucionais dos autores e intelectuais são fortemente lesados com a nova redação, tendo em vista que os interesses da sociedade seriam privilegiados em detrimento dos criadores. Mais que isso, aponta a constante falta de clareza na redação dos textos propostos. Outra preocupação do escritório que vale a pensa mencionar é a possibilidade de perda do direito dos autores de decidirem livremente sobre o uso de suas criações, criando a licença não voluntária que confere ao Presidente da República o poder (supremo) de autorizar em nome dos autores o uso de suas obras artísticas, literárias e científicas. Seguindo o processo expropriatório, o Poder Público, no lugar dos autores, determina o valor dos Direitos Autorais a serem pagos nessa situação. (BRAGA, 2010)

Vale a pena lembrar que o ECAD, embora discuta os direitos de "autores e intelectuais", tem interesses restritos à área de obras musicais. Isso, por sua vez, não o faz representante dos interesses dos autores pesquisadores e da comunicação científica.

Argumentos do SNEL

O Sindicato Nacional dos Editores de Livros (SNEL) também manifesta sua insatisfação ao Ministério da Cultura, seguindo a linha de crítica ao Anteprojeto de lei que propõe mudanças à LDA. De acordo com sua análise "[...] o texto preocupou-se muito mais em estabelecer uma função social do direito de autor do que propriamente darIhe a proteção como caberia neste sistema normativo." (SINDICATO..., 2015). Segundo o SNEL, a flexibilização pretendida pelo Ministério da Cultura desestimula a produção artística e intelectual brasileira, pois os autores perdem o retorno esperado e desejado da conclusão de seu produto. A flexibilização do Direito Autoral na realidade atinge o próprio sistema educacional, visto que prejudica o mercado de publicações no Brasil, que enfrenta sérias dificuldades econômicas. Sem um setor de livros forte, não é possível um desenvolvimento cultural satisfatório em país algum.

O Sindicato continua argumentando que na concessão de licenças não voluntárias o texto não é claro o suficiente, ou seja, não há critérios objetivos para a outorga de tais concessões, gerando incertezas para o meio artístico e intelectual. Além disso, o texto não leva em consideração a capacidade de publicação das Editoras, nem o advento das novas tecnologias, como o amplo acesso permitido pela internet aos mais diversos conteúdos. Os argumentos do Sindicato também citam que a falta de clareza e o excesso de poder outorgado ao Presidente podem levar a medidas e decisões tidas como abusivas.

As manifestações do ECAD e do SNEL são válidas e ajudam sobremaneira na discussão do tema apresentado, que se mostra bastante polêmico. Contudo, não se pode olvidar que tais entidades representam grupos de interesses e coalizões que teriam suas atividades econômicas diretamente afetadas pelas questões em comento.

\section{Argumentos do IBPI}

Os argumentos do Instituto Brasileiro de Propriedade Intelectual (IBPI) mostram uma impressão bastante positiva em relação às alterações propostas pelo Ministério da Cultura à LDA/98. Por meio de Nota, o Instituto 
defende que o direito de autor não está separado dos demais direitos e garantias do sistema jurídico brasileiro. Como todo sistema de proteção de direitos existentes no ordenamento jurídico pátrio, o sistema de Direito Autoral precisa estar em equilíbrio com os demais. Não há que se falar apenas em proteção aos autores e, muito menos, em proteção apenas dos interesses dos usuários das obras produzidas. Também argumenta o IBPI que o Anteprojeto está de acordo com as convenções internacionais sobre propriedade intelectual, já que ambas preveem o equilíbrio entre Direito Autoral e interesse coletivo, tais como acesso universal à cultura e desenvolvimento da educação. Além disso, a lista de uso livre de direito patrimonial sobre propriedades intelectuais, ou seja, o limite de livre exploração de obras por parte de seus autores, não ultrapassa o rol apresentado pela Convenção de Berna.

Ainda no mesmo documento, o Instituto analisa o Art. $5^{\circ}$, XXVII da Constituição Federal brasileira, especialmente no tocante a sua redação

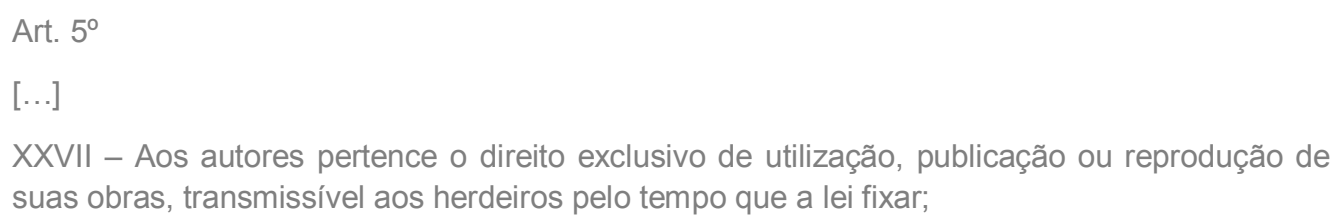

O termo "utilização" refere-se ao uso das obras dos autores em seu caráter patrimonial, ou seja, para o exercício de atividade econômica, uso este não garantido pelo texto da CF de 1988. O meio de expressão da atividade criativa é o que é passível de proteção, mas as ideias do autor são absorvidas pelo usuário que dá sua própria interpretação, baseado em seus conhecimentos, suas experiências e suas convicções pessoais. Por outro lado, a utilização privada da obra intelectual jamais poderá estar sujeita a um direito exclusivo de autor, que exigiria que aquele que tem contato com a obra não a incorpore ao seu patrimônio intelectual. (INPI, 2010)

Já a expressão "publicação" também se refere à atividade econômica, não se tratando de direito moral, mas patrimonial dos autores, tornando o direito de publicação uma prerrogativa patrimonial do autor. Seguindo o raciocínio exposto anteriormente, a Constituição brasileira assegura a proteção dos direitos de publicação nos casos em que gera resultados econômicos provenientes de uma relação de mercado.

Sobre a expressão "reprodução", o Instituto mantém a mesma lógica. A Constituição Federal confere proteção nos casos de aproveitamento econômico das obras do autor. Nos casos de reprodução para uso privado, não há a tutela jurídica do Direito Autoral.

Por fim, a Nota do IBPI menciona que a licença não voluntária é um excelente avanço na legislação sobre direitos de autor em nosso ordenamento jurídico. O que pode ser considerado como uma severa afronta a um direito fundamental, na verdade é um mecanismo para a garantia da harmonização do direito do acesso público à informação.

\section{Argumentos da Rede pela Reforma}

A Rede pela Reforma é a reunião de diversas entidades da sociedade civil, tais como Associação Nacional de Pós-Graduação e Pesquisa em Educação (ANPEd), Comunidade Brasileira de Recursos Educacionais Abertos (REA) e União Nacional dos Estudantes (UNE), para a discussão do Anteprojeto de lei que prevê mudanças para a Lei de Direitos Autorais. Após a realização de debates entre os participantes interessados, foi alcançado o consenso em alguns dos pontos de revisão.

A Rede entende como necessário o fim do limite à reprodução parcial ou integral de obras, desde que para fins privados, tentando garantir o fim social do acesso à cultura e à informação. A flexibilização da utilização e reprodução de obras culturais, artísticas e intelectuais, desde que respeitadas as condições de interesse coletivo e relevância social, é de extrema necessidade para o desenvolvimento educacional e cultural do país. Seu argumento está baseado em que a legislação brasileira está defasada em comparação ao resto do mundo, sendo que, nesse caso é um dos únicos países que ainda mantém tal restrição de reprodução. Defende, ainda, o uso de obras não apenas para uso privado, mas também para fins didáticos, por parte de professores e educadores na elaboração de suas aulas, sem ter que se preocupar com autorização expressa do autor e nem arcar com os custos referentes aos direitos autorais.

A proposta do Ministério da Cultura também é de grande valia ao desenvolvimento das atividades de biblioteca, visto ser possível o intercâmbio de obras de difícil acesso, além de permitir que bibliotecas preservem seus acervos por meio de fotocópias, sem necessidade de pagamento de Direitos Autorais, possibilitando melhor preservação do patrimônio cultural. Também é importante mencionar que bibliotecas poderão digitalizar os livros 
de seu acervo e disponibilizar para consulta livre dentro de suas dependências sem a prévia autorização dos autores das obras. Essa inovação soluciona a questão da limitação imposta aos frequentadores de bibliotecas quanto ao quantitativo de cópias disponíveis no acervo.

\section{Conclusões}

Os avanços das tecnologias de informação e comunicação possibilitaram o surgimento do Movimento do Acesso Aberto, consequência, na verdade, do interesse de pesquisadores em ter seus trabalhos o mais acessíveis possível. O Movimento favorece a permanência da titularidade do direito autoral com o autor, provocando reestruturações no sistema de comunicação científica. Entretanto, o fato de as editoras não quererem perder lucro no mercado editorial torna o Movimento em uma ameaça, na medida em que supera barreiras de custo e de permissão de uso da informação. Desse modo, os altos lucros das editoras tendem a diminuir e, com isso, o custo para acessar a informação tende a ser menor ao usuário, democratizando a disponibilização do conhecimento. Tudo isso requer que o tema seja tanto bem entendido quanto posto em prática, para o avanço do Movimento do Acesso Aberto à Literatura Científica. É necessário que o autor permaneça com a titularidade do Direito Autoral, parte patrimonial do direito autoral passível de transferência e exploração comercial. Os princípios que regem o Movimento favorecem isso por meio de contratos de autorizações como as licenças públicas e, mais especificamente, a Creative Commons.

Nota-se que a questão que permeia a dificuldade do avanço do Movimento é a falta de interesse e de conhecimento dos autores a respeito dos direitos autorais, e as editoras tiram proveito disso para lhes impor condições desfavoráveis. Com isso, o acesso à informação em periódicos, online ou não, é restringido, já que os titulares do direito autoral trocam o direito pela proposta de proteção oferecida pela editora. Na verdade, é sabido que essa proteção advém da lei e não de um protecionismo utópico oferecido pela editora, sendo importante, portanto, dar ao pesquisador uma clara indicação do que pode ou não pode ser feito com os conteúdos resultantes de seus trabalhos de pesquisa. Nesse contexto, autores e gestores de repositórios (em sua maioria bibliotecários), assumem novos e relevantes papeis no processo de comunicação científica, particularmente no que concerne a negociações com editores, utilização de licenças de uso, elaboração de políticas, dentre outros.

Para lograr um maior alcance de suas pretensões, o Movimento do Acesso Aberto deve centrar o foco no papel dos autores, verdadeiros titulares do Direito Autoral, como atores-chave na composição de sua coalizão institucional. Com isso, terão maior possibilidade de atuação junto a formuladores de políticas e tomadores de decisão para que o somatório final da atuação das instituições no cenário político possa tender para seus interesses.

Considerando a teoria da ACF, o Movimento do Acesso Aberto surge como um elemento novo no cenário da publicação científica e sua missão é ampliar o debate e, com isso, alterar o status quo encontrado, estabelecendo novas coalizões. Conforme mencionado anteriormente, os autores constituem um subgrupo que precisa ser convencido a formar coalizão pelo Acesso Aberto na comunicação científica.

No caso do Brasil, é possível inferir que o Movimento do Acesso Aberto, consoante mapeamento dos atores na consulta pública, seria formado por instituições como o IBPI e a Rede pela Reforma. No entanto, torna-se necessário incluir sociedades científicas e outras instituições de autores, formando uma coalizão pela eliminação das barreiras de custo e de acesso ao conteúdo científico produzido no meio acadêmico. Desse modo, a contribuição do Movimento do Acesso Aberto introduz no jogo político da comunicação científica, a necessidade de novas coalizões capazes de fazer frente àquelas formadas por instituições que almejam a manutenção do sistema que favorece apenas a editoras, coalizão formada por instituições tais como o ECAD e o SNEL.

De fato, as instituições que modelam os Direitos Autorais envolvem no mesmo bojo obras literárias, artísticas e científicas, o que dificulta as mudanças no âmbito da comunicação científica. Considerando que a obra científica exerce um papel diverso das obras literárias e artísticas, sua inclusão nos debates quanto aos direitos autorais em um único grupo faz com que outras coalizões de interesse participem das discussões para a mudança no sistema. Isso, por sua vez, prejudica sobremaneira o acesso à comunicação científica, visto que a maior quantidade de coalizões de interesse político dificulta o consenso e mesmo a tomada de decisão política.

A abordagem da ACF contribui para o entendimento desse cenário, oferecendo um modelo para identificação de coalizões que realmente reflitam a Agenda de uma nação no contexto da comunicação científica e do Movimento do Acesso Aberto. Dentre outras possibilidades, deve-se afastar do debate questões atinentes a obras literárias e artísticas, justamente pela diferença que apresentam. Focar no subgrupo específico da 
comunicação cientifica aumenta a participação e, por consequência, a importância de sua coalizão no jogo institucional de formação de políticas públicas.

\section{Referências}

ACEMOGLU, Daron; ROBINSON, James. Por que as nações fracassam?:as origens da prosperidade e da pobreza. Rio de Janeiro. Editora Campus, 2012

ARAÚJJO, Edmir Netto de Araújo. Proteção judicial do direito de autor. São Paulo: Ltr, 2004.

BARBOSA, Denis Borges; BARBOSA, Ana Beatriz Nunes. Direitos autorais e TRIPS. In: WACHOWICZ, Marcos; MORENO, Guillermo Palao (Coord.). Propriedade intelectual: inovação e conhecimento. Curitiba: Juruá, 2010. p. 111-140

BETHESDA STATEMENT ON OPEN ACCESS PUBLISHING, 2003. Disponível em:

$<$ http://dash.harvard.edu/bitstream/handle/1/4725199/suber bethesda.htm? sequence=1>. Acesso em: 25 maio 2013.

BOBBIO, Noberto. Dicionário de política. Brasília: UnB, 1998.

BONAFONT, Laura Chaqués. Redes de Políticas Públicas. Madri. CIS, 2004

BRASIL. Acordo sobre aspectos de propriedade intelectual relacionados ao comércio: acordo TRIPS ou ADPIC (1994). Disponível em:<http://www.cultura.gov.br/site/wp-content/uploads/2008/ 02/ac trips.pdf>. Acesso em:1 set. 2012.

BRASIL. Constituição da República Federativa do Brasil (1998). Disponível em: < http://www.planalto.gov.br/ccivil_03/constituicao/constituicao.htm>. Acesso em: 01 jan. 2014.

BRASIL. Decreto 75.699 de 06 de maio de 1975. Promulga a Convenção de Berna para a proteção das Obras Literárias e Artísticas, de 9 de setembro de 1886, rev. em Paris em 24 de julho de 1971. Disponível em:<http://www.cultura.gov.br/site/wpcontent/uploads/2007/10/decreto-75699.pdf>. Acesso em: 25 jul. 2013.

BRASIL.Lein. 496 de de agosto de 1898. Define e garante os direitos autorais. Disponível em:<http://www2.camara.gov.br/legin/fed/lei/1824-1899/lei-496-1-agosto-1898-540039-publicacao -39820-pl.html>. Acesso em: 3 set. 2012

BRASIL.Lei no 9.610, de 19 de fevereiro de 1998. Lei dos direitos autorais. Disponível em:<http://www.planalto.gov.br/Ccivil 03/ LEIS/L9610.htm>.Acesso em: 28 nov. 2008.

SINDICATO NACIONAL DOS EDITORES DE LIVROS. Brasília, 2010. Disponível em:<

http://www2.cultura.gov.br/consultadireitoautoral/wp-content/uploads/2010/09/SNEL1.pdf >. Acesso em: 14 dez. 2015.

BRASIL. Projeto de Lei n.1.120, apresentação em 21 de maio de 2007. Disponível em:

<http://www.camara.gov.br/proposicoesWeb/fichadetramitação?idProposicao=352237>. Acesso em: 30 jun.2013.

BUDAPEST OPEN ACCESS INITIATIVE (BOAI), 2002. Disponível em: <http://www.soros.org/openaccess/read>. Acesso em: 24 jun.2013.

CABRAL, Plínio. A nova lei de direitos autorais: comentários. 4.ed. SãoPaulo: Harbra, 2003.

COBB, R. W.; ELDER, C. D. Participation in America politics: the dynamics of agenda-building. 2.ed. Baltimore: Johns Hopkins University Press, 1983

DECLARAÇÃO DE BERLIM SOBRE ACESSO LIVRE AO CONHECIMENTO NAS CIÊNCIAS E HUMANIDADES, 2003. Disponível em: <http://oa.mpg.de/ files/2010/ 04/BerlinDeclaration_pt.pdf>. Acessoem: 25 ago. 2012.

FRIEND, Frederick J. Who protects the un-protected?.High Wycombe, UK, p.1-2, 2004.

GANDELMAN, Henrique. De Gutenberg à internet: direitos autorais na era digital. 4.ed. ampl.eatual. Rio de Janeiro: Record,2001.p.32.

GARVEY, D. W.; GRIFFITH B. C. Communication and information within scientific disciplines: empirical findings for physicology. In: Communication the essence of science. Oxford: Pergamon Press, 1979. p. 127-147

HAJER, Marteen.Policy wihtout polity?Policy analysis and the institutional void.Policy Sciences, n. 36, n. 2, p. 175- 195, jun. 2003.

HARNAD, S. Scholary Skywriting and the Prepublication Continuum of Scientific Inquiry. CurrentContents, n.45, p.9-13, nov. 1991. Disponível em: <http://eprints.soton.ac.uk/251894/1/harnad90.skywriting.html>. Acessoem: 9 set. 2012.

HURD, J.M.Scientific communication: new roles and new players. Science \& Technology Libraries, v.25, n.1, 2004, p.5-22. 
INSTITUTO Brasileiro de Propriedade Intelectual. Nota em comento ao Anteprojeto de lei de revisão da lei 9.610/98. Disponível em: <http://ibpibrasil.org/media/56847e971c9c8944ffff8156fffffffo.pdf>. Acesso em 21 de maio de 2013.

JONES, Bryan. Bounded Rationality and Political Science.Lessons from Public Administration and Public Policy. Journal of Public Administration Theory and Research.Vol 13, pp. 395-412.

KAHNEMAN, Daniel. Rápido e Devagar: Duas Formas de Pensar. Rio de Janeiro: Editora Objetiva, 2012.

KINGDON, John W. Agendas, Alternatives ad Public Policies. Boston: Longman, 2011.

KIM, Linsu. Technology transfer and intellectual property rights: the Korean experience. IPRS online, Genebra, Suíça, n.2, jun. 2003. Disponível em: <http://ictsd.net/downloads/2008/06/cs_kim.pdf>. Acesso em: dez. 2012.

LEITE, Eduardo Lycurgo. Plágio e outros estudos em direito de autor.Brasília: Lumen Juris, 2009

MAHONEY, James e THELEN, Kathleen.Explaining Institutional Change: Ambiguity, Agency and Power.Cambridge: Cambridge University Press, 2010.

MARCH, James G. Como as Decisões Realmente Acontecem: Princípios de Tomada de Decisões. São Paulo: Editora Leopardo, 2009.

MARANDOLA, Marco. Um nuevo derecho de autor?: introducción AL copyleft, acesso abierto y creativecommons. Barcelona: Derecho de autor, 2005.

OPEN ARCHIVES INITIATIVE, 1999. Disponível em: <http://www.openarchives.org/sfc/sfc.htm>. Acesso em: 24 ago. 2012

ORLANDO, Pedro. Direitos autorais. Brasília: Senado Federal, 2004.

ORTELLADO, Pablo; MACHADO, Jorge Alberto. Direitos autorais e o acesso aberto às publicações científicas, ADUSP, p.110, ago. 2006.

PIMENTA, Eduardo Salles. Princípios de direitos autorais: um século de proteção autoral no Brasil 1898 - 1998. Rio de Janeiro: Lumen Juris, 2004

PIMENTEL, Luiz Otávio; BARRAL, Welber. Direito de propriedade intelectual e desenvolvimento. In Propriedade intelectual e desenvolvimento. Florianopólis: Fundação Boitex, 2007. p.11-34.

PINHEIRO, Patrícia Peck. Direito digital. 4.ed. São Paulo: Saraiva, 2010.

PONTES, Hildebrando. Os contratos de cessão de direitos autorais e as licenças virtuais creativecommons. 2. ed. Belo Horizonte: Del Rey, 2009.

ROCHA, Thiago Gonçalves Paluma. Proteção da propriedade intelectual pelo TRIPS e transferência de tecnologia. In: BARRAL, Welber; PIMENTEL, Luiz Otávio. Propriedade intelectual e desenvolvimento. Florianopólis: Fundação Boitex, 2007. p.149-172.

SANTOS, Manuela. Direito autoral na era digital: impactos, controvérsias e possíveis soluções. São Paulo: Saraiva, 2009.

SECCI, Leonardo. Políticas públicas: conceitos, esquemas de análise, casos práticos. 2. ed. São Paulo: Cengage Learning, 2013.

SEN, Amartya. Desenvolvimento como liberdade. Tradução de Laura Teixeira Motta. São Paulo: Companhia das letras, 2000.

SOUTO, Patrícia Cristina Nascimento; OPPENHEIM, Charles. Direitos autorais e o movimento do acesso aberto: um equilíbrio que demanda novas atitudes. In: FERREIRA,Sueli Mara Soares Pinto; TARGINO, Maria das Graças (Org.). Mais sobre revistas científicas: em foco a gestão. SãoPaulo: Senac São Paulo,2008.

WEIBLE, Christopher; SABATIER, Paul; JENKINS-SMITH, Hank C.; al all. A Quarter Century of the Advocacy Coalition Framework. The Policy Studies Journal, 2011: 349-460.

WILLINSKY, John. The access principle :the case for access to research and scholarship. Cambridge, MA: MIT Press,2006.

ZAHARIADIS, Nikolaos. The Multiple Streams Framework; structure, limitations, prospects. In: SABATIER, Paul(editor). Theories of the Policy Process.California: University of California, Davis Westview Press, 2007. 


\section{Dados das autoras}

\section{Larissa Melo Bezerra de Oliveira}

Graduada pelo Centro Universitário de Brasília em Direito e pela Universidade de Brasília em Biblioteconomia, especialista em Propriedade Intelectual pela World Intellectual Property Organization, mestre em Ciência da Informação pela Universidade de Brasília. Atualmente é gestora da Biblioteca Digital do Ministério Público Federal.

laramelooliveira@gmail.com

\section{Sely Maria de Souza Costa}

Possui graduação em Biblioteconomia pela Universidade de Brasília (1974), especialização em Análise de Sistemas pela ETUC (Universidade Católica de Brasília, 1980), mestrado em Biblioteconomia e Documentação pela Universidade de Brasília (1992) e doutorado em Ciência da Informação - Loughborough University (1999). Atualmente é professora adjunta aposentada da Universidade de Brasília. Foi diretora da Biblioteca Central da Universidade de Brasília de março de 2009 a junho de 2010 e membro nato do Conselho Editorial da Editora da Universidade de Brasília no mesmo período. Professora visitante e co-orientadora de dissertação de mestrado na Universidade do Minho / Departamento de Sistemas de Informação, entre 2006 e 2010. Sua experiência na área de Ciência da Informação é em Processos da Comunicação, atuando principalmente nos seguintes temas: publicações eletrônicas, comunicação científica, acesso aberto, comunicação organizacional e comunicação e cidadania (comunitária). Realiza também estudos nas áreas de Gestão da Informação e de Gestão do Conhecimento (organizacional e científico) e trabalha com a Metodologia de Sistemas Flexíveis (Soft Systems Methodology) como método de pesquisa. Coordenou o projeto de repositório institucional da UnB, em parceria entre o CID e a BCE, assim como o Ibict. Coordenou, ainda, o Projeto de Repositório de Objetos Digitias de Aprendizagem da UnB, além de outros projetos da Biblioteca Digital da BCE. Presidiu o comitê organizador de duas conferências internacionais e participa regularmente como membro de comitê organizador e como parecerista e membro do comitê científico de quatro conferências internacionais e de vários eventos nacionais. É, ainda, parecerista em várias revistas brasileiras.

selmar@unb.nr

Recebido - Received: 2015-09-05

Aceitado - Accepted: 2015-12-18

\section{(cc) $\mathrm{BY}$}

This work is licensed under a Creative Commons Attribution 4.0

United States License.

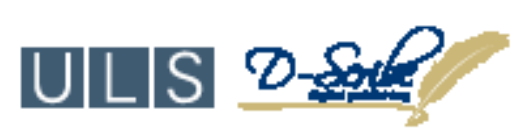

This journal is published by the University Library System of the University of Pittsburgh as part of its D-Scribe Digital Publishing Program and is cosponsored by the University of Pittsburgh Press. 